\title{
PRÁTICAS PEDAGÓGICAS NA PEDAGOGIA WALDORF: uma análise sobre a percepção de professores em formação
}

\author{
PRÁCTICAS PEDAGÓGICAS EN LA PEDAGOGÍA WALDORF: un análisis de la \\ percepción del profesorado en formación
}

\section{PEDAGOGICAL PRACTICES IN WALDORF EDUCATION: an analysis of the perception of teachers in training}

\author{
Edna Martins ${ }^{1}$ \\ https://orcid.org/0000-0003-2795-1503 \\ Renata Marcílio Cândido ${ }^{2}$ \\ http://orcid.org/0000-0002-8032-881X
}

\begin{abstract}
Resumo
Este trabalho apresenta dados de pesquisa qualitativa realizada no curso de Pedagogia de uma universidade pública de São Paulo. Tal estudo foi desenvolvido na unidade curricular "Práticas Pedagógicas e de Pesquisa" que visa contribuir com a formação inicial de professores oportunizando momentos de imersão em ambientes fora da universidade, inserindo o estudante no mundo da pesquisa científica. O objetivo do trabalho foi compreender quais as principais percepções de futuros pedagogos sobre as práticas educativas de escola de Pedagogia Waldorf. A metodologia consistiu na análise de relatórios escritos de 25 estudantes, sobre práticas educativas e funcionamento de uma escola privada de Pedagogia Waldorf da cidade de São Paulo. Tais registros foram construídos após a observação participativa desses alunos em atividades da Educação infantil e Ensino fundamental da escola selecionada para a pesquisa. Os resultados demonstraram que a maioria dos futuros professores desconhece essa abordagem no campo da Educação, mas avalia que muitas de suas práticas pedagógicas podem ser úteis no trabalho educativo da escola pública. Concluiu-se que os cursos de formação inicial de professores na contemporaneidade carecem de maior aproximação de perspectivas pedagógicas não tradicionais, que visem apresentar possibilidades de práticas educativas criativas e humanizadoras a partir de um olhar crítico, com vistas a melhoria do trabalho cotidiano de educadores de escolas públicas

\footnotetext{
${ }^{1}$ Doutorado em Psicologia da Educação - PUC/SP. Professora da Universidade Federal de São Paulo (Unifesp). Grupo de estudos e pesquisa em processos educativos e perspectiva Histórico-Cultural (GEPPEDH), do NAI Núcleo de Acessibilidade e Inclusão e do NEAB - Núcleo de estudos Afro-brasileiros da Unifesp. E-mail: edna.martins@unifesp.br

${ }^{2}$ Doutorado em Educação - USP. Professora da Universidade Federal de São Paulo (Unifesp). Grupo de Pesquisa 'História da Educação: Intelectuais, Instituições, Impressos" (Unifesp). E-mail: remarcilio@gmail.com
}

\section{Como referenciar este artigo:}

MARTINS, E.; CÂNDIDO, R.N. Práticas Pedagógicas na Pedagogia Waldorf: uma análise sobre a percepção de professores em formação. Revista Pedagógica, v. 23, p. 1-18, 2021. 
brasileiras. Constatou-se também, a necessidade de mais estudos sobre a metodologia das escolas de Pedagogia Waldorf no Brasil.

Palavras-chave: Educação alternativa. Práticas educativas. Formação de professores.

\title{
Resumen
}

Este artículo presenta datos de una investigación cualitativa realizada en un curso de pedagogía en una Universidad pública de São Paulo. Este estudio se desarrolló en la unidad curricular "Prácticas Pedagógicas y de Investigación" que tiene como objetivo contribuir con la formación inicial de los docentes brindando oportunidades de inmersión en entornos fuera de la universidad, insertando al estudiante en el mundo de la investigación científica. El objetivo del trabajo fue comprender cuáles son las principales percepciones de los futuros pedagogos sobre las prácticas educativas de una escuela de Pedagogía Waldorf. La metodología consistió en el análisis de informes escritos de 25 estudiantes, sobre las prácticas educativas y el funcionamiento de una escuela privada de Pedagogía Waldorf en la ciudad de São Paulo. Dichos registros se construyeron luego de la observación participativa de estos estudiantes en actividades de educación infantil y primaria de la escuela seleccionada para la investigación. Los resultados mostraron que la mayoría de los futuros docentes desconocen este enfoque en el campo de la Educación, pero evalúan que muchas de sus prácticas pedagógicas pueden ser útiles en la labor educativa de la escuela pública. Se concluyó que los cursos de formación inicial del profesorado en la contemporaneidad necesitan una aproximación más cercana a las perspectivas pedagógicas no tradicionales, que pretenden presentar posibilidades de prácticas educativas creativas y humanizadoras desde un punto de vista crítico, con miras a mejorar el trabajo diario de educadores de escuelas públicas brasileñas. También se constató la necesidad de realizar más estudios sobre la metodología de las escuelas de pedagogía Waldorf en Brasil.

Palabras clave: Educación alternativa. Prácticas educativas. Formación de profesores.

\begin{abstract}
This paper presents data from qualitative research carried out in a pedagogy course at a public University in São Paulo. This study was developed in the curricular unit "Pedagogical and Research Practices" which aims to contribute to the initial training of teachers by providing opportunities for immersion in environments outside the university, inserting the student in the world of scientific research. The objective of the work was to understand what are the main perceptions of future teachers about the educational action of a Waldorf Pedagogy school. The methodology consisted of the analysis of written reports of 25 students, on educational practices and the functioning of a private school of Waldorf Pedagogy in the city of São Paulo. Such records were built after the participatory observation of these students in activities of early childhood and elementary education of the school selected for the research. The results showed that the majority of future teachers are unaware of this approach in the field of Education but evaluate that many of their pedagogical practices can be useful in the educational work of the public school. It was concluded that the initial teacher training courses in contemporary times need a closer approximation of nontraditional pedagogical perspectives, which aim to present possibilities of creative and humanizing educational practices from a critical point of view, with a view to improving the daily work of educators from Brazilian public schools. It has shown that there is also a need for further studies on the methodology of Waldorf Pedagogy schools in Brazil.
\end{abstract}

Keywords: Alternative education. Educational practices. Teacher training. 


\section{INTRODUÇÃO}

A Pedagogia Waldorf foi desenvolvida por Rudolf Steiner no início do século XX, em 1919 em Stuttgart, na Alemanha. No ano de 2019 completou 100 anos. A primeira Escola Waldorf foi criada com o objetivo de atender os filhos de operários da fábrica de cigarros Waldorf-Astória. Depois da primeira escola fundada por Steiner, outras instituições com a mesma proposta foram inauguradas na Inglaterra, Holanda, Suíça e em outros países. Palmer (2005) aponta como ocorreu o crescimento da Pedagogia Waldorf na primeira metade do século XX, assinalando como se tornou uma alternativa à escolaridade oficial no pós-guerra na Alemanha, fazendo parte importante de movimentos reformistas educacionais, em prol de uma “Nova Educação”.

No Brasil, tal Pedagogia se expandiu a partir do ano de 1956 com a fundação da primeira escola em São Paulo por Rudolf Lanz que acreditava que a proposta pedagógica poderia proporcionar aos estudantes o despertar harmonioso de todas as capacidades humanas no campo físico, psicológico e espiritual, tendo como meta o desenvolvimento pleno do indivíduo. Para ele a Pedagogia de Steiner, anunciava-se como uma ciência mais abrangente que a ciência natural, com explicações baseadas em uma visão do universo e do homem (LANZ, 1998).

Silva (2015) explica que a Pedagogia de Steiner se ancora na Antroposofia e inaugura uma nova forma de educar crianças e adolescentes, tendo como princípio uma concepção mais integral e holística a partir da práxis pedagógica que tem como modelo de ação a unidade coesa no desenvolvimento biológico, psicológico, emocional e espiritual do educando. Para a Antroposofia:

[...] o ser humano é uma entidade constituída de corpo, alma e espírito - aos quais estão relacionadas, respectivamente, as faculdades do fazer, do sentir e do pensar. Embora latentes desde o momento no nascimento físico do homem, cada um desses constituintes tem um desabrochar que segue uma progressão baseada em ciclos de sete anos, denominados "setênios". Uma vez que, a cada novo setênio, a energia vital do ser humano apresenta-se especialmente investida em um aspecto específico desse desenvolvimento, acarretando modificações biológicas, fisiológicas e cognitivas peculiares, todo o currículo Waldorf apresenta-se também orientado para atitudes e dispositivos didáticometodológicos diferenciados em cada uma dessas etapas (SILVA, 2015, p. 108). 
Segundo Romanelli (2008), Steiner buscava a concretização de um impulso social para que humanidade pudesse evoluir em prol da justiça e da liberdade. Para ele, somente a partir daí, poderia ser desenvolvida a trimembração social, sustentada por meio de ideais de fraternidade, igualdade e liberdade. Essa proposta só seria possível "numa sociedade em que os homens se educassem para isso" (p. 153). Sendo assim, as escolas de Pedagogia Waldorf foram paulatinamente, criadas em todo o mundo por pessoas, grupos ou comunidades que aspiravam tais ideais. Com o passar do tempo, cada uma dessas escolas construiu sua própria identidade, que responde por sua formação e administração, a depender da localização geográfica, histórica e social.

A condução de uma escola Waldorf segue hierarquia também bastante diferente daquelas conhecidas em outros espaços educativos. O conjunto de famílias, assim como os professores e funcionários envolvidos no ambiente educacional Waldorf formam uma comunidade escolar com poder de decisão em várias instâncias. Desse modo, tanto professores, como mães e pais, irmãos e irmãs das crianças que vivenciam a Pedagogia de Steiner são pilares de funcionamento da instituição. Cada família pode ter seu papel definido a partir de sua possibilidade de participação e o seu envolvimento pode significar o diferencial na educação tanto de seus filhos quanto dos demais alunos da escola. Segundo Pinto (2009), ao escolher a Pedagogia Waldorf para a educação da criança, a família deve estar consciente da sua relação direta com a escola e de suas responsabilidades dentro e fora do espaço escolar, não depositando unicamente na instituição a responsabilidade pela formação do filho.

Outro diferencial das escolas de Pedagogia Waldorf está no modo singular de suas gestões. A administração escolar opera sem fins lucrativos e caracteriza-se por:

[...] uma grande flexibilidade e maleabilidade, buscando adaptar-se ao que exigissem as circunstâncias. Não existe nenhuma estrutura hierárquica como diretor ou equipe administrativa. Essas funções são exercidas por um professor devidamente habilitado que responde pela escola perante a Secretaria da Educação. As demais funções administrativas são exercidas pela associação e pelo corpo docente. À associação mantenedora cabe a responsabilidade pela manutenção e funcionamento [...] O corpo docente, por sua vez, cuida das metas e dos objetivos da escola, responsabilizando-se pela execução e avaliação do trabalho escolar [...] Pais, professores e pessoas simpatizantes compõem essa associação (ROMANELLI, 2008, p. 154). 


\section{REVISTA}

Segundo a Federação das Escolas Waldorf no Brasil, criada em 1996 com o objetivo de coordenar as ações das instituições dessa natureza, a primeira escola Waldorf brasileira nasceu a partir da iniciativa de um grupo de amigos, estudiosos das obras de Steiner, que entusiasmados pela Antroposofia resolvem fundar uma escola Waldorf em l956, em São Paulo. Com a contribuição de professores ligados à Pedagogia na Alemanha, inicia-se o processo de formação de professores para trabalharem com tal metodologia e, assim nasce a "Escola Waldorf Rudolf Steiner".

Após a expansão da Pedagogia de Steiner no Brasil, recentemente ocorreu a criação da primeira faculdade de Pedagogia Waldorf brasileira em São Paulo. Nas duas últimas décadas houve um crescimento exponencial de iniciativas Waldorf por todo o país. Na cidade de São Paulo, há escolas bem conhecidas como o "Colégio Waldorf Micael” e a “Escola Waldorf São Paulo", dentre outras de menor porte que atendem principalmente a Educação Infantil.

Segundo Fadel e Souza (2019), embora as escolas de Pedagogia Waldorf tenham se expandido nos últimos 60 anos no Brasil, ainda há poucas iniciativas de escolas públicas que utilizam o currículo e as premissas de Steiner. A primeira experiência de escola pública com currículo Waldorf surgida no país ocorreu em meados de 1970, em Camanducaia/MG. Já no Rio de Janeiro, em Nova Friburgo, há duas iniciativas públicas de escolas Waldorf em condições e contextos diferentes. Outra escola pública Waldorf inaugurada em 2016 é a Escola Municipal de Educação Infantil “Dr. José Calumby Filho, localizada em Aracaju/Sergipe como a primeira experiência do Nordeste" (p. 96). Além dessas, há outras ações de grupos de entusiastas da Pedagogia Waldorf em condução, espalhadas pelo país.

Partindo da importância da Pedagogia de Steiner para os processos educacionais, assim como da experiência de formação inicial de professores no curso de Pedagogia de uma Universidade Pública Federal de São Paulo, o objetivo deste trabalho foi compreender quais as principais percepções de futuros pedagogos sobre as práticas educativas de uma escola de Pedagogia Waldorf. Com esse foco, o desenvolvimento da unidade curricular em que se deu a pesquisa, ocorreu por meio de encontros de estudos, leituras, oficinas e outras atividades com base em tal perspectiva, antes que os estudantes pudessem ter contato com o trabalho de campo, buscando construir conhecimento sobre essa abordagem pedagógica no que se refere à modalidade de Educação Infantil e Séries iniciais. 
Tal iniciativa teve origem na necessidade assinalada pelos futuros professores de terem acesso às iniciativas pedagógicas não tradicionais e, pelo fato de que nos últimos anos, a expansão da Pedagogia Waldorf ter aguçado o interesse de profissionais da educação que procuram o conhecimento de novas práticas pedagógicas num mundo em transformação.

\section{METODOLOGIA}

A disciplina Práticas Pedagógicas e de Pesquisa (PPP) é dividida em várias linhas de estudos e a escolha de cada uma dessas linhas é realizada pelos alunos. Tem como objetivo a realização de ações que possam levar o estudante de Pedagogia ao conhecimento de práticas educativas diferenciadas e a inserção dos alunos no campo da pesquisa científica. Os encontros na universidade e as investigações de campo visam desenvolver conhecimentos que articulem a dialética teoria/prática. Espera-se que os estudantes possam conhecer experiências educativas diferenciadas nos mais diversos contextos, oportunizando a aproximação com modos de educar em suas multideterminações. Além de estudos teóricos, constam como ações da disciplina, pesquisa de campo, a partir de metodologia pré-estabelecida com a orientação de professores que supervisionam turmas de até 15 alunos.

A linha "Práticas educativas na Pedagogia Waldorf", teve como principal objetivo levar aos estudantes o conhecimento sobre a Pedagogia Waldorf, principalmente no que se refere às ações pedagógicas empreendidas no campo da Educação Infantil e Anos iniciais. A metodologia de abordagem qualitativa, consistiu na participação de 25 estudantes de ambos os sexos que tiveram como ações de pesquisa a observação de um dia de atividades em evento de uma Escola Waldorf da rede privada de São Paulo, além de oficinas com professores com formação em seminário Waldorf e conversas com pais da mesma instituição. O foco das observações foram as práticas educativas da Educação Infantil e Anos Iniciais e os espaços e materiais utilizados na escola. Apesar das publicações científicas sobre a Pedagogia Waldorf serem escassas, as atividades de pesquisa foram subsidiadas por estudos teóricos sobre a abordagem e a apresentação de trabalhos manuais e cadernos de crianças da escola observada, constituintes do acervo da pesquisadora orientadora. 
A análise dos dados foi baseada em registros de relatórios finais dos estudantes com suas percepções e reflexões críticas sobre as práticas educativas e os espaços da escola pesquisada. A organização e interpretação dos dados ocorreu fundamentada na proposta de Aguiar e Ozella (2006) que propõem a construção de núcleos de significação para a compreensão de registros de um dado fenômeno estudado. As categorias de análise foram construídas levando em conta o objetivo da pesquisa, a partir de indicadores e similaridades dos relatos escritos pelos estudantes, possibilitando a elaboração das reflexões aqui apresentadas.

Os excertos citados nesse trabalho foram retirados dos relatórios dos estudantes de Pedagogia, com nomes fictícios, garantindo o anonimato e os cuidados éticos prescritos em pesquisas dessa natureza.

\section{CONHECIMENTOS SOBRE A PEDAGOGIA WALDORF}

No Brasil, a Pedagogia Waldorf é uma das teorias pedagógicas que mais se apresenta à margem dos cursos de formação de professores. Hardiman (2013, p. 13) aponta que “embora a Pedagogia Waldorf apresente contribuições significativas e enriquecedoras para pensar a formação integral do professor e da criança" verifica-se uma grande ausência de discussões sobre tal enfoque. Essa questão foi constatada a partir dos relatos dos estudantes da disciplina ofertada, visto que em sua maioria, nunca tinha ouvido falar de tal abordagem, como nos seguintes registros: "O pouco que eu sabia é que se tratava de uma escola muito diferente de qualquer outra escola, com um estilo rústico, mas não conhecia quais essas diferenças" (Valéria). "Sabia que era um tipo de pedagogia alternativa" (Luana). "De primeira, imaginei ser uma pedagogia totalmente burguesa e fora da normalidade" (Diana). "Antes da disciplina, eu achava que as Escolas Waldorf deixavam as crianças com o tempo livre para fazer o que quisessem" (Graziela).

Além de demonstrarem conhecimentos distorcidos sobre a Pedagogia, alguns estudantes consideraram e discutiram nos relatórios a questão das práticas e do seu currículo que, historicamente não se propõe a focar o aprendizado dos alunos tendo em vista a formação/treino para o vestibular ou na entrada dos estudantes na Universidade: 
Apenas tinha ouvido falar que era algo para quem tem um poder aquisitivo muito alto e que era uma pedagogia alternativa fora dos padrões escolares "clássicos" normativos e que muito dos alunos não passariam em vestibulares por terem estudado com essa pedagogia (Sônia).

Frequentemente as escolas que trabalham com a pedagogia Waldorf são acusadas de não darem a devida atenção às áreas mais duras das ciências, tais como a matemática, a física ou a biologia, por exemplo, e privilegiarem áreas poucos trabalhadas nas escolas mais tradicionais, como é o caso das Artes. Outra questão pela qual a escola é também mal compreendida, diz respeito à sua prática pedagógica que não admite o treino exaustivo dos alunos, com demasiada quantidade de conteúdos que buscam a aprovação dos seus estudantes em vestibulares mais concorridos. Sobre o ensino voltado para o vestibular, Bach Júnior e Guerra (2018) assinalam o compromisso da escola em transmitir o conhecimento acumulado pela humanidade aos jovens da contemporaneidade. Além disso, a grande disputa que ocorre nos exames e provas dos vestibulares, tem contribuído para que professores e administradores de escolas Waldorf possam repensar os currículos. Muito se tem discutido sobre a questão dos exames de seleção das universidades e a preparação do jovem para o mundo do trabalho, embora "a formação dada ao aluno pela Pedagogia Waldorf põe um fim na concepção de que o sistema de ensino é mero fornecedor de capacidade para o sistema de trabalho" (ROMANELLI, 2008, p. 166).

Em outro relato uma estudante reafirma as dúvidas que apareceram no grupo e chega a questionar a idoneidade da Pedagogia: "Inicialmente, sem estudar a fundo sobre a Pedagogia, pensava que era um pouco desordenada e duvidava de sua seriedade..." (Nívea). Nessa mesma direção, outros estudantes relataram aspectos genéricos sobre as práticas pedagógicas, demonstrando falta de conhecimento sobre o assunto.

[...] sabia que era uma pedagogia um tanto desvinculada do tradicional, pois ocorrem práticas que estimulam o desenvolvimento do ser humano, como tricô, preparo do alimento, além de um contato maior com a natureza. E assim tais características despertaram meu interesse em conhecer um pouco mais sobre essa pedagogia (Melissa).

De modo geral, todos os estudantes após participarem de discussões sobre a teoria que embasa a Pedagogia Waldorf e realizarem atividades em oficinas e rodas de conversa 
com professores da escola, demonstraram em seus registros, mudanças consideráveis de suas percepções iniciais:

Foi muito importante para minha formação ter contato com uma linha pedagógica que considera a criança e o jovem de forma integral, trabalhando inclusive a dimensão espiritual. A Pedagogia Waldorf visa o desenvolvimento do educando de forma livre, lúdica, com ênfase nas artes e no trabalho manual. Essa disciplina foi essencial para que eu pudesse de fato entender essa pedagogia, visto que por meio dela pude conhecer uma escola Waldorf, aprender práticas pedagógicas por eles desenvolvidas (Regina).

As mudanças vieram em relação ao conhecimento geral, pois através dos textos discutidos em sala de aula e das visitas das professoras que atuam diretamente com a Pedagogia Waldorf, me proporcionaram conhecer a trajetória histórica (origem, fundador, co-fundadores), importância social, as vivências da rotina de alguns colégios em São Paulo, relatos das professoras visitantes e os principais fundamentos que a estruturam (Paloma).

Antes de ter contato com a Pedagogia criada por Steiner, os estudantes tinham conhecimento de que a escola possuía caráter assumidamente de base cristã que permeava suas práticas educativas. Descobriram na pesquisa que ainda que o ensino religioso não seja transmitido como dogmático e doutrinário é "ministrado pelas várias confissões e comunidades religiosas e também como "ensino religioso cristão livre" pelos educadores da escola, conforme apontado por Richter (2002, p. 7,8). Diante da coleta de informações sobre a escola e, observação da realidade, os registros escritos demonstraram a mudança da visão inicial e preconceituosa dos estudantes:

[...] Apesar de criar resistência sobre esse tipo de ensino por ser de base religiosa, pude me desconstruir muito, pois não tem um intuito moralista, no qual a religião é o principal, sendo imposta para seus alunos, ela permeia, falam sobre as figuras religiosas, mas sempre de forma muito respeitosa e permissiva, podendo os alunos criarem suas concepções sobre os ensinamentos e os possibilitando ser de outras religiões, pois em todas as histórias não ficava claro uma religião central, são de bases cristãs, mas sempre brandas no modo de contar e chegar aos alunos (Mirian).

A teoria desenvolvida e discutida em sala de aula, também ampliou os saberes dos estudantes sobre a Pedagogia Waldorf:

[...] Aprendi um pouco sobre a história da origem e das bases dessa pedagogia idealizada por Rudolf Steiner e baseada na Antroposofia; sobre a divisão do desenvolvimento humano e das aprendizagens em setênios; sobre as práticas que 
estimulam o desenvolvimento integral do ser humano; sobre o período que o professor acompanha uma turma; entre outros aprendizados (Melissa).

Conheci a Pedagogia Waldorf que é baseada a partir da antroposofia, pautada no bom desenvolvimento das crianças. [...] A educação se organiza dando uma grande importância na fase do desenvolvimento da criança que é a cada setênio, ou seja, de sete em sete anos (Lidiane).

Os setênios (períodos de sete anos) são entendidos na Pedagogia Waldorf como etapas de desenvolvimento do ser humano com mudanças significativas no indivíduo. Saraiva e Zucolotto (2020, p. 8) afirmam que cada setênio representa momentos de clara diferenciação na vida da criança ou do jovem em que vão surgindo novos "interesses, perguntas latentes e necessidades concretas". Nas escolas de Pedagogia Waldorf um dos principais alicerces teóricos é a perspectiva dos setênios, pois ao pensar o desenvolvimento dos alunos em cada um desses períodos, significa também organizar práticas educativas que possam auxiliá-los no despertar de suas individualidades e potencialidades.

Uma das práticas educativas que caracterizam a o trabalho pedagógico na escola Waldorf e bem pouco conhecida no campo educacional é a euritmia - técnica artística indicada por Steiner para o trabalho pedagógico - que significa um modo de expressão capaz de transformar poesia, narrativas e palavras em movimentos. Nessa perspectiva, é comum que nos primeiros anos escolares, alguns contos de fadas sejam poetizados e trabalhados euritmicamente. O conhecimento sobre os "setênios" e euritimia também foi registrado pelos estudantes.

Depois dessa disciplina, tomei ciência sobre a organização dessa pedagogia em setênios, o olhar para o desenvolvimento físico, espiritual, intelectual e artístico do aluno, valorizando o ser humano e dando menos importância para o treinamento para provas, a Educação Infantil que se aproxima da rotina de casa, a forte presença dos trabalhos manuais, euritmia e arte (Ivana).

Além dos registros que demonstram o desconhecimento inicial dos estudantes e as suas descobertas após o contato com a Pedagogia, notou-se uma gama de observações e vivências acerca da instituição visitada, configurando um panorama das práticas pedagógicas e da organização dos espaços e tempos da escola Waldorf. 


\section{PERCEPÇÕES SOBRE ESPAÇOS DA ESCOLA E PRÁTICAS EDUCATIVAS DA PEDAGOGIA WALDORF}

A vivência dos estudantes num dia da escola de Pedagogia Waldorf possibilitou a imersão na realidade e nas práticas pedagógicas vividas pelas crianças no espaço educativo. As conversas com pais e professores também deram aos estudantes dimensões daquilo que é realizado durante os primeiros anos escolares nesse contexto. Os estudantes se surpreenderam, principalmente com os ambientes e a organização dos materiais de cada atividade educativa desenvolvida com as crianças.

O que mais me prendeu na visita técnica ao Colégio Waldorf foi como tudo parece ser milimetricamente pensado e elaborado para que traga uma melhor experiência educativa para todas as crianças, sempre pensando no que tal objeto/experiência/prática pedagógica poderia proporcionar à criança. (Júlio)

A experiência na escola também possibilitou comparações com as práticas pedagógicas tradicionais, deixando nítidas as questões da organização do tempo e dos espaços escolares que expressam modos de compreender a infância e a influência de cada ambiente nos contextos de desenvolvimento.

\footnotetext{
Nas práticas escolares tudo é completamente humanizado, ou seja, o educando é visto como um ser íntegro que merece ser respeitado, cuidado e educado da melhor forma possível e não como mais um que deverá somente produzir mais em menos tempo para o mercado de trabalho, como na lógica neoliberal das escolas tradicionais, assim, cada elemento dentro da Pedagogia Waldorf é envolvido por diversos significados, nada é feito ou utilizado aleatoriamente, tudo é minuciosamente pensado, planejado e estudado antes para que possibilite bons efeitos nas crianças. (Ligia)
}

O modelo tradicional de escola tende a ter um padrão estrutural que pode transmitir à maioria das crianças sensações de formalidade e frieza. Na maioria das escolas tradicionais, assim como os espaços, os tempos e momentos dedicados ao brincar tendem a limitar a ação da criança pequena à ambientes em que o período de escolarização pode significar um tempo de poucas alegrias, como compara a estudante Luciana:

O que mais me chamou atenção foi a valorização da criança e como eles dão importância ao brincar e a autonomia. Em contraste com a escola no qual sou professora auxiliar, onde as crianças de 5 anos, tem lição de casa todos os dias, 6 apostilas por semestre e brinquedoteca somente uma vez na semana (Lucia). 
Tradicionalmente, as escolas de Pedagogia Waldorf têm em sua grande maioria, arquitetura simples, comportando premissas voltadas a espaços mais acolhedores e humanizadores, respeitando os tempos de ser criança e os processos de desenvolvimento, como apontaram os estudantes:

O ambiente em que está localizada a escola Waldorf me surpreendeu bastante, não imaginava que a escola era uma espécie de chácara e tinha ambientes tão simples iguais aos que vimos, além de que a escola está cercada de árvores que podem ser exploradas pelas crianças. Outro aspecto que me surpreendeu foram as salas de aula da Educação Infantil, fiquei encantada com os tons pasteis da sala, com os objetos de altura e tamanho que atendam as crianças, com as bonecas dispostas que foram produzidas pelas crianças, com os desenhos em cima da mesa, com a cabana, com a simplicidade da sala e sua beleza; fiquei encantada com a disposição da sala, até mesmo com os ganchos onde as crianças penduram suas mochilas e possuem uma marca de suas mãos na parede para identificar. 0 ambiente onde são realizadas as peças é incrível, pois é muito simples, mas muito lindo, com cenários e objetos produzidos pelas próprias crianças e pais. (Adriana)

Sobre a organização dos ambientes na Pedagogia Waldorf, Santos et al (2015) assinalam que no caso dos prédios em que funcionam essas escolas há um planejamento focado nos modos como se concebe o projeto dos ambientes escolares. Ainda que a segurança e funcionalidade do ambiente escolar sejam aspectos de grande importância, na Pedagogia Waldorf os modos como se dão as práticas pedagógicas e os usos desses espaços se sobrepõem a outros fatores. Sendo assim, "a paisagem e o ambiente fornecem importantes elementos para a educação da percepção e para o desenvolvimento físico e anímico das crianças e jovens" (SANTOS et al., 2015, p. 123).

A configuração do espaço de aula caracterizada como peculiar das instituições Waldorf comparando com modelo de escola tradicional com certeza me chamou atenção, me sentia em casa, seguro e confortável, todo o ambiente é planejado para essa sensação. Além de achar o local extremamente lindo, bem adaptado (transformado de casa/sítio em escola) o acesso a materiais naturais e o contato direto com a natureza torna a experiência da criança muito mais significativa na perspectiva de (re)descobrimento do mundo por parte da criança e na existência simbológica de que o mundo é belo. Com certeza o "cantinho" que mais me marcou na visita ao colégio Micael foi a área recreativa, tanto da Educação Infantil quanto do Fundamental, composto por belas árvores e o chão com terra e folhagens me recordava da escola na qual estudei no interior... (Pedro).

Para além da edificação e organização dos espaços da escola, os estudantes também observaram aspectos sobre a valorização dos elementos que na perspectiva da 
metodologia Waldorf remetem a um maior contato com a natureza. Pesquisas de Oliveira e Cunto (2015) destacam que tal Pedagogia concebe o interior das salas de aulas como espaços privilegiados de vivência com formas simples que proporcionem um contexto agradável de aprendizagem, promovendo a socialização, criatividade e pensamento crítico. As recomendações são que em vez de materiais plásticos e sintéticos, se dê preferência para a madeira nas edificações e no mobiliário. As práticas pedagógicas atuam a partir de elementos como tecidos coloridos, gravetos, folhas de árvores, bonecos de pano e outros materiais naturais, como descreve a estudante:

\begin{abstract}
Há também o claro vínculo das práticas com a natureza, dessa forma, o ano letivo é dividido em épocas - 3 a 4 semanas - que acompanham as estações, as educadoras sempre agradecem a mãe-natureza antes comer, incentivam a admirá-la, ensinam a respeitá-la e, principalmente, a experienciá-las - crianças Waldorf têm muito contato com a natureza. [...] Me chamou muito atenção também a contação de histórias realizada no jardim de infância. As crianças escutam a mesma história durante um bom tempo e esta história é sempre um clássico, na versão mais próxima possível da original. A contação é feita com poucos elementos, alguns panos coloridos e bonecas sem rosto, para que seja incentivada a imaginação e a criatividade da criança. A hora da história é extremamente valorizada para Pedagogia Waldorf na formação das crianças, esse momento só começa com total silêncio e é iniciado com o toque acalentador das cordas do kântele e uma música gentilmente cantada pela professora. (Vanessa).
\end{abstract}

Sobre o currículo e o modo de compreensão dos setênios na Pedagogia Waldorf, os estudantes estranharam algumas especificidades observadas na escola ao tomarem conhecimento de que na metodologia Waldorf há apenas um(a) professor(a) que acompanha uma classe do primeiro ao oitavo ano do Ensino Fundamental. Sobre essa questão, Saraiva e Zucolotto (2020) esclarece que:

[...] cada grupo de alunos que ingressa no primeiro ano terá um(a) professor(a) que acompanhará essa turma durante os oito anos do Ensino Fundamental. Além de ministrar as matérias básicas para as quais estiver apto, através da intensa convivência, o professor tem a possibilidade de conhecer em profundidade cada criança e pode desenvolver um acompanhamento mais individualizado e balizado nas necessidades de cada uma delas. O professor da classe acompanha o grupo em viagens de estudo, estabelece o elo entre as famílias das crianças e objetiva criar um grupo social integrado entre elas (p. 09).

Os estudantes identificaram a relação professor-aluno como o centro da Pedagogia Waldorf. O educador é considerado um dos pilares do processo educativo e deve conhecer 
intima e profundamente cada um de seus alunos para que seu trabalho tenha êxito. É, portanto, comum que os professores conheçam a família de cada criança, além de suas casas, relações sociais e atividades extra- escolares.

$\mathrm{O}(\mathrm{a})$ professor(a) de classe, como é chamado(a) o(a) educador(a) que atua no ensino fundamental, demonstra uma das peculiaridades desta Pedagogia, causando estranheza aos alunos pesquisadores: “(...) o que achei inusitado é a questão de uma professora acompanhar a mesma turma durante um longo período (8 anos) uma vez que em minha formação escolar eu passei por diversas educadoras (Vanessa).

O que mais me chamou atenção dentro das práticas da Pedagogia Waldorf, foi o fato de que uma/um prof. permanecerá com a mesma classe durante sete anos, completando um ciclo com os mesmos educandos que se iniciou. Contrário do que se acredita dentro do senso comum, no qual se dissemina a ideia de que é necessário a troca anual de prof. para que a criança não crie nenhum tipo de "costume" ou "apego, no sentido negativo da palavra, associando à um entrave para o seu pleno desenvolvimento, a Waldorf mostra que em nada prejudicaria seu ensino caso a mesma/mesmo prof. permaneça durante um ciclo inteiro com as mesmas crianças (Alice).

O fato de um(a) professor(a) permanecer durante oito anos com a mesma turma, acompanhando o processo de desenvolvimento de cada um de seus alunos parece ter sido uma das descobertas que causou maior impacto nos estudantes de Pedagogia. A maioria nunca tinha ouvido falar dessa prática, já que na escola tradicional raramente um professor acompanha uma turma por mais de um ano letivo.

O que eu achei mais estranho na pedagogia Waldorf foi um professor somente ficar com um aluno durante 7 anos, [...]. Acho que muito da nossa visão é formatada e domesticada pelo padrão tradicional escolar, tive muita estranheza pois não consigo imaginar isso acontecendo em uma escola de ensino público por exemplo. (Mariana)

Uma outra estudante aponta esse estranhamento, questionando a formação geral do professor no trabalho de 8 anos ensinando aos alunos todas as matérias do currículo:

O ponto que mais me deixou um pouco intrigada com a pedagogia Waldorf foi o fato de ter apenas uma professora para ensinar todas as matérias para as crianças e adolescentes. Por mais que o docente receba uma formação específica sobre a pedagogia Waldorf, acredito que seja um pouco complicado tanto para o docente quanto para o discente. (Nádia) 
Sobre essa permanência do professor, essa parece ser uma das especificidades da Pedagogia Waldorf, podendo ser "possível a permanência do professor principal de uma classe com o mesmo grupo de alunos, do $1^{\circ}$ ao $8^{\circ}$ ano do ensino fundamental", sendo responsável por disciplinas como "língua materna, matemática, ciências, história, geografia" (BACH JUNIOR, et al., 2012, p. 89).

Um professor que trabalha com a Pedagogia Waldorf está em constante processo de formação. Deve ser uma personalidade interessada em questões sociais da atualidade, além de manter uma busca incessante por conhecimentos de todas as áreas. Seu conhecimento funciona como ponte entre seus alunos e o contexto social e cultural em que vivem. Espera-se que "o professor seja um profundo conhecedor do mundo e da cultura de sua época, procurando compreender o que significam as diferentes correntes e movimentos culturais de seu tempo" (SARAIVA E ZUCOLOTTO, 2020, p. 10).

Outra questão bastante discutida foi sobre a participação das famílias na escola, que difere singularmente da forma como historicamente essa relação tem ocorrido na escola pública tradicional, como apontado nos estudos de Marafon e Tondin (2010). Diferentemente das escolas tradicionais, a escola Waldorf tem como uma de suas premissas fundamentais a participação de pais, mães e irmãos na escola. Sobre esse tema, os registros dos estudantes assinalam esse envolvimento dos familiares: “(...) achei muito interessante o envolvimento das famílias com a escola, na realização de oficinas e bazares" (Graziela); “(...) achei inusitada a questão dos pais sempre estarem envolvidos nos projetos das escolas, pois em outros colégios os pais só são chamados para ver o que foi produzido pelo filho, já na Waldorf, os pais produzem também” (Lúcia).

Nas escolas de Pedagogia Waldorf, antes da criança ser matriculada, os pais são convidados a conhecer as várias formas em que podem participar efetivamente das atividades escolares. O calendário letivo envolve diferentes eventos, festas e comemorações nas quais os pais devem estar envolvidos. Segundo Pinto (2009), a participação das famílias não se dá apenas pela presença na escola e não se resume no acompanhamento das atividades escolares dos filhos, mas espera-se que desenvolvam uma “íntima” relação com a escola (PINTO, 2009, p. 26).

Depois de todas as descobertas relativas às Práticas educativas da Pedagogia Waldorf, no final do semestre letivo, alguns estudantes mostraram-se interessados em 
realizar outras pesquisas que tivessem como ênfase a relação família-escola na escola tradicional e nas escolas de Pedagogia Waldorf.

\section{CONSIDERAÇÕES FINAIS}

Com o objetivo de ampliar os conhecimentos sobre práticas pedagógicas dos estudantes de Pedagogia, essa experiência se mostrou exitosa, já que os alunos puderam vivenciar o ambiente, contexto e práticas de uma proposta pedagógica ainda pouco disseminada nos espaços acadêmicos. A experiência se mostrou rica, também a partir da perspectiva da investigação científica, visto que estudantes puderam aplicar técnicas de pesquisa na compreensão sobre a Pedagogia Waldorf. Os relatórios finais são prova disso, já que os registros dos estudantes cumpriram satisfatoriamente aspectos importantes de estudos qualitativos com dados fidedignos. Outra questão importante foi a possibilidade de um olhar atento para as práticas pedagógicas da escola Waldorf, num processo de reflexão crítica, sobretudo na perspectiva da escola pública brasileira.

Embora a criação e implementação de escolas Waldorf, historicamente tenha se dado a partir das classes sociais mais abastadas e, a maioria das instituições dessa natureza, pelo seu caráter privado, tenha inviabilizado o acesso dos filhos da classe trabalhadora, principalmente nos grandes centros urbanos, há diferentes experiências de tal Pedagogia implantadas em escolas públicas por todo o mundo, incluindo o Brasil. Esse foi um dos pontos discutido pelos estudantes em momentos de estudos e de visita à escola.

Os estudantes trouxeram em seus registros percepções pontuais sobre as especificidades das práticas educativas da Pedagogia Waldorf considerando as crianças como agentes de desenvolvimento na observação e discussão de práticas que envolvem brinquedos e brincadeiras, contato com a natureza, plantio e preparo de alimentos, trabalhos artísticos e manuais, contação de histórias e musicalização. Na discussão sobre suas percepções debateram sobre tais práticas pedagógicas, considerando possibilidades de serem realizadas no contexto da escola pública com a intenção de buscar formas de maior humanização dos processos educativos por meio de objetos simples, naturais e de baixo custo. 
O registro de tais experiências por meio de relatos orais e narrativas escritas também é ponto a ser destacado, não apenas pela forma original de apreensão das experiências realizadas na disciplina, mas também por apresentar-se como um importante instrumento para a pesquisa, para a reflexão sobre as práticas educativas, assim como para a formação inicial e continuada dos profissionais da Educação.

Nessa perspectiva, ainda que o campo da pesquisa científica sobre o currículo, procedimentos metodológicos e práticas pedagógicas concernentes à Pedagogia Waldorf seja incipiente (SANTOS; GOMES, 2021), consideramos ser uma área bastante promissora, frente a expansão das escolas dessa abordagem no Brasil, além das especificidades do método e da variedade de questões norteadores de pesquisa.

Concluiu-se a partir da análise dos registros, que os cursos de formação de professores precisam estar atentos às possibilidades de oportunizar formas de atuação dos estudantes que favoreçam o conhecimento de práticas pedagógicas inovadoras, além de proporcionar atividades capazes de desenvolver o senso crítico por meio da inserção de futuros professores no mundo da pesquisa científica.

\section{REFERÊNCIAS}

AGUIAR, Wanda Maria Junqueira; OZELLA, Sergio. Núcleos de significação como instrumento para a apreensão da constituição dos sentidos. Psicologia: ciência e profissão, v. 26, n. 2, p. 222-245, 2006.

BACH JUNIOR, Jonas; GUERRA, Melanie Gesa Mangels. O currículo da Pedagogia Waldorf e o desafio da sua atualização. Revista e-Curriculum, v. 16, n. 3, p. 857-878, 2018.

BACH JUNIOR, Jonas et al. Professores Waldorf: educar para a liberdade é superar determinismos. Educação e Fronteiras, v. 2, n. 6, p. 87-102, 2012.

FADEL, Sabrina; SOUZA, Rita de Cássia de. Jardim da Manga: Nascimento e morte de uma experiência de implantação da pedagogia Waldorf em uma escola pública/Jardim da Manga. Educação em Foco, v. 22, n. 37, p. 92-113, 2019.

HARDIMAN, Júlia Soares. Educação, infância e Pedagogia Waldorf: a formação docente em questão. Mestrado em Educação, UFSC, 2013.

LANZ, Rudolf. A pedagogia Waldorf: caminho para um ensino mais humano. 6. ed. São Paulo: Antroposófica, 1998. 
OLIVEIRA, Thais Cardoso e; CUNTO, Ivanoé de. Colaborações de arquitetura, psicologia e pedagogia waldorf para escolas. Cadernos de ensino e pesquisa, 2015.

MARAFON, Patrícia Sabina; TONDIN, Celso Francisco. Participação das famílias na escola e contribuições da Psicologia Escolar na mediação desta relação. Revista Pedagógica, v. 12, n. 25, p. 227-255, 2010.

PINTO, Juliana. A escolha de escolas Waldorf por famílias das camadas médias.

Dissertação (Mestrado) - Universidade Federal de Minas Gerais, Belo Horizonte, 2009.

RICHTER, Tobias. Objetivo Pedagógico e Metas de Ensino de uma Escola Waldorf. São

Paulo: Federação das Escolas Waldorf no Brasil, 2002

ROMANELLI, Rosely A. Pedagogia Waldorf: um breve histórico. Revista da Faculdade de Educação, v. 8, n. 10, p. 145-169, 2008.

PINTO, Juliana da Silva Sardinha. A escolha de Escolas Waldorf por famílias de camadas médias. 2009. 126f. Dissertação (Mestrado em Educação) - Programa de Pós-Graduação em Educação, Universidade Federal de Minas Gerais, Belo Horizonte.

SANTOS, Ana Cristina Souza dos et al. Autonomia, liberdade, criatividade e transdisciplinaridade em uma escola pública. Conhecimento \& Diversidade, v. 5, n. 10, p. 86-96, 2013.

SANTOS, Eliane Souza Oliveira dos; GOMES, Cleomar Ferreira. Pesquisas Brasileiras stricto sensu sobre a pedagogia waldorf: estudo exploratório. Brazilian Journal of Development, v. 7, n. 4, p. 38931-38943, 2021.

SARAIVA, Gabriela Luz; ZUCOLOTTO, Marcele Pereira da Rosa. A pedagogia Waldorf e a Base Nacional Comum Curricular na formação da criança. Research, Society and Development, v. 9, n. 10, p. e7279108754-e7279108754, 2020.

SILVA, Dulciene Anjos de Andrade. Educação e ludicidade: um diálogo com a Pedagogia Waldorf. Educar em Revista, n. 56, p. 101-113, 2015. 